\title{
Cieogratia
} Malavsian Ioumal of Societvand Space

\section{The effect of personality traits on collaborative consumption participation}

\author{
Abu Hanifah Ayob ${ }^{1}$, Zafir Khan Mohamed Makhbul ${ }^{1}$ \\ ${ }^{1}$ Faculty of Economics and Management, Universiti Kebangsaan Malaysia \\ Correspondence: Abu Hanifah Ayob (email: abuhanifah.ayob@ukm.edu.my)
}

Received: 01 March 2020; Accepted: 15 May 2020; Published: 30 May 2020

\begin{abstract}
The advancement of digital technology has refined the way traditional business operates. The new business model of collaborative consumption is not only novel, but potential customers are reluctant to participate. Who, then, is actually interested in embracing this new approach? To provide empirical evidence, this study attempts to examine the effects of the Big Five personality traits: agreeableness, neuroticism, extraversion, openness, and conscientiousness, on the propensity to participate in collaborative consumption. Drawing on the Student Behavior Survey 2019/2020 of 386 university students in Malaysia, we find that personality is not a strong predictor of collaborative consumption. In short, agreeableness increases the likelihood of participating in collaborative consumption and openness exhibits a negative effect; other traits have no effect.
\end{abstract}

Keywords: big five personality, collaborative consumption, Malaysia, personality traits, student behavior survey, university students.

\section{Introduction}

Collaborative consumption (CC), often interchangeable with similar terms for the sharing economy or peer-to-peer economy, is rooted in a comprehensive introduction by Felson and Spaeth (1978). Later, Botsman and Rogers (2010) refined the concept that eventually became a popular business model today. In brief, CC refers to the sharing of access to underutilized goods or services between providers and customers, thus emphasizing co-utilization over pure ownership (Schor \& Fitzmaurice, 2015). In other words, CC enables both parties to share, exchange, and rent goods or services without necessarily owning them (Choi et al., 2014). Successful examples of CC are Airbnb (accommodation-sharing) and Uber (ridehailing).

Unlike conventional businesses, $\mathrm{CC}$ is only available through community-based online or mobile technological platforms (Hamari et al., 2016). CC is beneficial for the community at large following the practice of sharing (with fees) under-utilized assets with other people in order to reduce the need for ownership (Stephany, 2015). In fact, early CC apps were not-for-profit based, including CouchSurfing and Freecycle (Belk, 2014). Today, CC serves not to maximize profit, but rather as a means to combat environmental and social problems like poverty, hyper-consumption, and pollution (Botsman \& Rogers, 2010; Hamari 
et al., 2015). Using under-utilized goods more efficiently can also save scarce resources which would otherwise be exploited for mass production (Bocker \& Meelen, 2017).

Despite the above-mentioned advantages, $\mathrm{CC}$ does not yet receive the full support of customers. Many hesitate to use CC since the model involves 'sharing' that is absent in a traditional business transaction when a seller transfers absolute ownership to a buyer upon settlement. Thus, research on factors explaining the willingness of individuals to participate in $\mathrm{CC}$ has progressed substantially in recent years. However, the existing literature focuses heavily on the effect of product-related variables on CC; customers are interested in using CC only if the product/service offered is financially beneficial (Milanova \& Mass, 2017; Tussyadiah, 2015) and perceivably less risky (Lee et al., 2018). Also, the likelihood of reusing CC also increases when the experience of using the platform is enjoyable (Hamari et al., 2015; Zhang et al., 2019) and satisfying (Mohlmann, 2015). While these studies merit acknowledgement, little is known about the effect of the customers' personality and its potential influence on the decision to participate (or not) in CC. Indeed, this is a considerable dearth in literature because personality has long been recognized as a dominant approach for representing the human trait structure (Roccas et al., 2002) which largely affects the subsequent behavior of individuals (Gohary et al., 2014).

To fill this gap, this study attempts to examine the effect of the Big Five Personalities (BFP): agreeableness, neuroticism, extraversion, openness, and conscientiousness, on the propensity to use CC. As a contextual contribution, we test our model utilizing data from the Student Behavior Survey 2019/2020 amongst 386 university students in Malaysia. Millennials are an important demographic, but are mostly neglected in business-marketing research. Although the spending capability of students is often limited, they are well-educated with strong technological competency and are one of the main internet users (Hu et al., 2009). According to the Internet Users Survey 2018 by the Malaysian Communications and Multimedia Commission, full-time students represent around 12.1 percent of total internet users in Malaysia. Also, the largest group of internet users is individuals at age of 20's. Thus, university students provide an insightful context for research exploration.

\section{Literature review}

Literature in many disciplines has drawn widely on the BFP of McCrae and Costa (1990) to illustrate the personality of individuals. BFP maps personalities onto five dimensions: agreeableness, neuroticism, extroversion, openness and conscientiousness. Theoretically, every person possesses all the traits, but on a different scale; e.g. an individual can demonstrate strong agreeableness and extroversion traits, but be weak in neuroticism, openness, and conscientiousness.

For this reason, BFP is found influential to many socio-economic aspects such as human resource management (Caligiuri, 2000) and technological development (Antoncic 2009). Surprisingly, few studies have investigated the relationship between the BFP and the usage of CC despite the fact that personality is a vital predictor of the economic decisions of individuals and the subsequent outcomes achieved (Cobb-Clark \& Schurer, 2012).

Instead, most research on the determinants of $\mathrm{CC}$ examine external product-related factors. For example, intention to adopt $\mathrm{CC}$ is driven by the perception of its value (Zhu et al., 2017) and other social factors such as social benefits (Tussyadiah, 2016) and social interactions (Guttentag et al., 2017). On the other hand, distrust, unpredictability, and lack of cost benefits make customers reluctant to use CC (Tussyadiah \& Pesonen, 2016; Tussyadiah, 2015). To fill the gaps, we draw on the authentic definition of each personality trait in BFP and conceptualize it in the context of CC business model. 


\section{Agreeableness}

An agreeable personality describes individuals who are caring, forgiving, kind, modest, obedient, and cooperative, as opposed to short-tempered, cruel, and distrustful (Roccas et al., 2002). Based on those traits, there are several reasons to anticipate that someone with an agreeable personality is more likely to participate in CC. As the philosophy of CC lies mainly on the concept that sharing is beneficial for society at large, it is more appealing to customers who value their communities and the environment (Guttentag, 2015; Tussyadiah, 2015). Also, CC is highly compatible with the 'soft personality' traits of agreeableness, generosity and trust; $\mathrm{CC}$ serves as a means of enacting benevolence by helping others and supporting the community (Albinsson \& Perera, 2012; Ozanne \& Balentine, 2010).

Hypothesis 1: Agreeableness increases the propensity to participate in collaborative consumption.

\section{Neuroticism}

Synonymous with emotional instability, neuroticism manifests anxiousness, depression, sadness, and insecurity (Roccas et al., 2002). Thus, it is reasonable to expect that neuroticism impedes the likelihood to try $\mathrm{CC}$ because these individuals prefer to be isolated and unsociable (Leong et al., 2017). Instead, strong trust is essential as a law protection is largely absent in CC framework (Hofmann et al., 2017). As CC strongly promotes the value of sharing, it is embraced only by those who can tolerate and trust other people, which is contradictory to neuroticism.

Hypothesis 2: Neuroticism decreases the propensity to participate in collaborative consumption.

\section{Extroversion}

Individuals with an extroverted personality exhibit sociable characteristics such as being active, energetic, and talkative (Rocca et al., 2002). These traits are consistent with the CC model that encourages physical communication between the provider and customer. For example, Airbnb and Couchsurfing do not only offer an exciting staying experience (Poon \& Huang, 2017; Tussyadiah \& Pesonen, 2016), but also promote social interactions between the guest, host, and the local community (So et al., 2018).

Hypothesis 3: Extroversion increases the propensity to participate in collaborative consumption.

\section{Openness}

Openness reflects strong creativity, curiosity, and imagination (Roccas et al., 2002). Individuals with this personality continuously reach out for new things and ideas, including participating in CC. Most importantly, CC offers a unique experience every time the customer uses it. For example, a traveler can meet up with different Uber drivers and Airbnb hosts with authentic hospitality (Poon \& Huang, 2017) and enjoy a more intimate experience compared to a taxi or hotel service. Similarly, Lang and Armstrong (2018) posit that customers with openness trait are proactively seeking and willing to explore unfamiliar things including the new $\mathrm{CC}$ trend. 
Hypothesis 4: Openness increases the propensity to participate in collaborative consumption.

\section{Conscientiousness}

Conscientiousness refers to carefulness, organization, thoroughness, responsibility, and trustworthiness (Roccas et al., 2002). Because CC is mostly based on availability (the provider only advertises the service when they are not using it), it is perhaps less preferable for conscientious customers who are looking for certainty in conventional providers such as a hotel or taxi company. In other words, the potential risks and uncertainties due to lack of knowledge in new CC business models have deterred individuals from using it (Lee et al., 2018; So et al., 2018).

Hypothesis 5: Conscientiousness decreases the propensity to participate in collaborative consumption.

\section{Method}

This study exploits data from the Student Behavior Survey (SBS) 2019/2020 which attempts to represent a national sample of Malaysian university students. Thus, the SBS is the most updated and comprehensive dataset available for understanding many aspects of student behavior. That includes the intention to either become an entrepreneur or social entrepreneur, online shopping behavior, and preference for buying local or imported products. From that, several research have been conducted utilizing the SBS dataset. In addition, the SBS also collects information on personal demographics and family backgrounds. The SBS is distributed across the country among university students from both public and private institutions, different levels (undergraduate and postgraduate), and in various study fields. It originally received 466 responses. However, after data cleaning to remove incomplete responses and outliers, only 386 entries are useful for analysis.

The descriptive analysis of SBS respondents is presented in Table 1. Most of them are female ( 80 percent) with the average age of 21 years old. The majority (90 percent) study at public universities and more than half (60 percent) take science courses. Most respondents have a good academic performance with an average cumulative grade point average (CGPA) of 3.35 out of 4.00 . Lastly, most of the respondents (60 percent) represent low-income families, followed by middle-income families (30 percent) and high-income families (10 percent).

Table 1. Descriptive analysis of SBS respondents

\begin{tabular}{ccc}
\hline Variable & Description & Measurement \\
\hline Gender & $79.8 \%=$ Female & $0=$ Female, $1=$ Male \\
& $20.2 \%=$ Male & \\
Age & Mean $=21.6$ years old & Continuous \\
CGPA & Mean $=3.35 / 4.00$ & Continuous, between 0.00 to 4.00 \\
Field & $61.1 \%=$ Social Science & $0=$ Social Science, $1=$ Science \\
& $38.9 \%=$ Science & \\
University & $11.9 \%=$ Private & $0=$ Private, $1=$ Public \\
& $88.1 \%=$ Public & \\
Family Income & $60 \%=$ Low & Dummy, middle income as a reference group \\
& $27 \%=$ Middle & \\
& $13 \%=$ High & \\
\hline
\end{tabular}




\section{Variables}

Unlike prior studies that focus on a specific CC application such as Airbnb (Lutz et al., 2018), Uber (Lee et al., 2018) and mobile CC (Zhu et al., 2017), we expand the definition of CC and measure in dichotomous form "Do you personally use sharing services such as Airbnb and Uber?"; 1 for Yes and 0 for No.

The explanatory variables, five personality traits, are captured on a five-point Likert scale, ranging from 1 (Strongly Disagree) to 5 (Strongly Agree) for the questions adopted from the Big Five Personality Inventory of John and Srivastava (1999), shown in Table 2. All constructs in the study show good internal consistency with Cronbach's alpha ranging between 0.512 and 0.857 .

Lastly, we control for demographic factors of the individual: gender, age, CGPA, study field, institution (public or private university), and family income group.

Table 2. Factor analysis results for explanatory variables

\begin{tabular}{ccccc}
\hline Scale and Item & $\boldsymbol{\alpha}$ & Loadings & Eigen Value & \% Variance explained \\
\hline Agreeableness & 0.776 & & 1.933 & 13.808 \\
Considerate and kind & & 0.804 & & \\
Helpful and unselfish & & 0.863 & & \\
Trustworthy & & 0.755 & & \\
Neuroticism & 0.806 & & 1.352 & 15.405 \\
Depressed & & 0.862 & & \\
Moody & & 0.863 & & 16.848 \\
Nervous & 0.857 & 0.797 & & \\
Extraversion & & 0.876 & & \\
Talkative & & 0.834 & & 16.054 \\
Energetic & & 0.892 & & \\
Sociable & 0.512 & & & \\
Openness & & 0.847 & & \\
Curious & & 0.716 & & \\
Thinker & 0.693 & 0.759 & \\
Conscientiousness & & 0.860 & & \\
Reliable & & 0.743 & & \\
Efficient & & & \\
Planner & & & \\
Varimax rotation with Kaiser Normalization. $\alpha$ is the value of Cronbach's Alpha.
\end{tabular}

\section{Results and discussion}

To ensure data robustness, we check for non-response bias by comparing the demographics of early (received within one month) and late (received after one month) responses. Based on two-sample t-test, we found no significant difference between the two groups. Also, we checked for common method bias through Harman's one-factor test; no single factor accounted for most of the covariance in the independent and dependent variables (Podsakoff et al., 2003). The bivariate correlations amongst all variables are displayed in Table 3. From that, there is no clear evidence that multicollinearity might exist as all correlations are ranged between -0.479 and 0.179 , below than +-0.800 . 
Table 3. Correlational table

\begin{tabular}{rccccccccc}
\hline & Variables & $\mathbf{1}$ & $\mathbf{2}$ & $\mathbf{3}$ & $\mathbf{4}$ & $\mathbf{5}$ & $\mathbf{6}$ & $\mathbf{7}$ & $\mathbf{8}$ \\
\hline 1 & Gender & 1.000 & & & & & & & \\
2 & Age & 0.079 & 1.000 & & & & & & \\
3 & CGPA & 0.047 & -0.201 & 1.000 & & & & & \\
4 & Field & 0.128 & -0.197 & -0.073 & 1.000 & & & & \\
5 & University & -0.173 & -0.077 & -0.170 & 0.064 & 1.000 & & & \\
6 & Low-Income & -0.085 & -0.088 & -0.005 & -0.167 & -0.042 & 1.000 & & \\
7 & High-Income & 0.066 & 0.026 & -0.124 & 0.121 & 0.051 & -0.479 & 1.000 & \\
8 & CC & -0.065 & -0.069 & 0.067 & -0.066 & 0.034 & 0.106 & 0.028 & 1.000 \\
9 & Agreeableness & 0.029 & -0.069 & -0.101 & -0.044 & 0.179 & 0.099 & -0.063 & 0.015 \\
10 & Neuroticism & -0.051 & -0.197 & -0.039 & 0.057 & 0.039 & 0.036 & 0.062 & -0.105 \\
11 & Extraversion & -0.009 & 0.035 & -0.078 & -0.161 & 0.055 & 0.123 & -0.017 & 0.086 \\
12 & Openness & 0.018 & 0.116 & 0.006 & 0.037 & 0.085 & -0.048 & 0.068 & 0.065 \\
13 & Conscientiousness & -0.005 & 0.040 & 0.061 & -0.049 & 0.006 & -0.124 & -0.093 & 0.061 \\
\hline
\end{tabular}

This research employs logit regression to estimate the effect of five personality traits on the likelihood of using CC. Table 4 exhibits the findings of the hypothesis testing. Model 1 examines the controls, model 2 tests the independent variables, and model 3 runs the full model. The result of table 4 is presented below.

Even though all models are statistically significant, the explanatory power is very low with the Nagelkerke $\mathrm{R}^{2}$ standing at 0.091 . From that, we argue that personality traits are not a powerful force influencing CC participation among university students.

Only two personalities significantly predict the propensity of CC use: agreeableness (hypothesis 1) and openness (hypothesis 4). Neuroticism, extraversion and conscientiousness are all insignicant, thus rejecting hypotheses 2, 3, and 5. In general, adopting BFP framework to predict CC usage is not a sound empirical approach. CC is still a new business model whereas only a handful of applications commonly used amongst customers in Malaysia. In particular, GRAB ride-hailing is far more popular in Malaysia than Airbnb, Neighbor, and Rover; although these apps are very common especially in the United States. For this reason, customers are not fully understand the features, thus reluctant to try one regardless of their personalities.

Although the effect is found significant, openness actually decreases the likelihood of participating in $\mathrm{CC}$, rejecting hypothesis 4 . The findings are somewhat a counter-intuitive in general since most studies suggest a positive effect of openness on the excitement in joining CC (Poon \& Huang, 2017). Instead, our negative results suggest that individuals with open personalities are less likely to use CC. In attempt to shed light on this, we argue one possible reason is that individuals with a strong openness trait continuously seek new experiences and do not stick to one thing for long. Since they exhibit high curiosity (Roccas et al., 2002), open customers opt to buy services using different platforms: traditional and CC interchangeably. Hence, they are not always enticed by the features of $\mathrm{CC}$ but easily switch to conventional providers following a tempting promotion (e.g. a hotel that offers a new experience of staying in an aquarium-surrounded room).

Lastly, our controls favor that students with better academic performance from lowand high-income families (as compared to middle-income families) are more likely to use CC than their fellow students. As mentioned earlier, $\mathrm{CC}$ practice in perhaps still new in Malaysia. Then, only those with more exposure to information (better academic performance) are likely to adopt CC. In terms of the economic status, we argue that there might be different reasons why low and high-income (family) students are found using CC more often. The former could be because they prefer to rent rather than own a possession as it is a cheaper option, whilst the latter is due to the fact that rich people often more aware about latest technology applications than middle-income people. 
Table 4. Logit regression of collaborative consumption participation

\begin{tabular}{|c|c|c|c|}
\hline & Model 1 & Model 2 & Model 3 \\
\hline Agreeableness & & $\begin{array}{c}0.213^{\gamma} \\
(0.129)\end{array}$ & $\begin{array}{c}0.213 \\
(0.140)\end{array}$ \\
\hline Neuroticism & & $\begin{array}{c}0.155 \\
(0.134)\end{array}$ & $\begin{array}{c}0.113 \\
(0.139)\end{array}$ \\
\hline Extraversion & & $\begin{array}{c}0.176 \\
(0.136)\end{array}$ & $\begin{array}{c}0.138 \\
(0.143)\end{array}$ \\
\hline Openness & & $\begin{array}{c}-0.278^{*} \\
(0.139)\end{array}$ & $\begin{array}{l}-0.301 * \\
(0.146)\end{array}$ \\
\hline Conscientiousness & & $\begin{array}{c}0.045 \\
(0.133)\end{array}$ & $\begin{array}{c}0.115 \\
(0.138)\end{array}$ \\
\hline Gender & $\begin{array}{c}-0.295 \\
(0.326)\end{array}$ & & $\begin{array}{c}-0.294 \\
(0.343)\end{array}$ \\
\hline Age & $\begin{array}{c}-0.071 \\
(0.082)\end{array}$ & & $\begin{array}{l}-0.023 \\
(0.086)\end{array}$ \\
\hline CGPA & $\begin{array}{c}0.680 \\
(0.451)\end{array}$ & & $\begin{array}{c}0.860^{\gamma} \\
(0.459)\end{array}$ \\
\hline Field & $\begin{array}{l}-0.280 \\
(0.288)\end{array}$ & & $\begin{array}{l}-0.166 \\
(0.299)\end{array}$ \\
\hline University & $\begin{array}{c}0.321 \\
(0.408)\end{array}$ & & $\begin{array}{c}0.213 \\
(0.442)\end{array}$ \\
\hline Low-Income & $\begin{array}{l}0.731 * \\
(0.300)\end{array}$ & & $\begin{array}{l}0.731 * \\
(0.316)\end{array}$ \\
\hline High-Income & $\begin{array}{c}0.856^{\gamma} \\
(0.458)\end{array}$ & & $\begin{array}{l}1.045^{*} \\
(0.490)\end{array}$ \\
\hline Constant & $\begin{array}{c}0.177 \\
(2.735)\end{array}$ & $\begin{array}{c}1.563 * * * \\
(0.138)\end{array}$ & $\begin{array}{c}-1.390 * * * \\
(2.827)\end{array}$ \\
\hline Model $\chi^{2}$ & $13.227^{\gamma}$ & $10.184^{\gamma}$ & $22.137 *$ \\
\hline -2 Log Likelihood & 352.261 & 355.304 & 343.351 \\
\hline Predictive Accuracy (\%) & 81.9 & 81.9 & 81.9 \\
\hline Nagelkerke $\mathrm{R}^{2}$ & 0.055 & 0.043 & 0.091 \\
\hline
\end{tabular}

\section{Conclusion}

In recognizing the importance of the digital economy and its benefits, stakeholders, including the government, providers, and customers cannot afford to avoid embracing related business models such as collaborative consumption or the sharing economy. More importantly, as Malaysia is progressively moving towards a developed nation status, customers must embrace the modern technologies without hesitation. However, like other cutting-edge applications, adopting $\mathrm{CC}$ is not always supported by all users. Some are still reluctant, perhaps because of unfamiliarity with the features or simply because of their personality.

To offer empirical evidence, we examine the relationship between the BFP and the propensity of using CC. It is our hope that this study sheds light on the individual intrinsic determinant that pushes customers into participating in the digital economy application of CC. This study should advances literature by complementing prior research mainly studied external factor of the product features.

We develop five hypotheses and test them using the SBS data amongst 386 university students from various academic and family background in Malaysia. The findings strongly indicate that personality traits are not a dominant factor for predicting the likelihood of using CC. Of the five personalities tested, only agreeableness increases the propensity; whilst 
neuroticism, extraversion, and conscientiousness show no significant effect. Lastly, individuals with an open personality are found to participate less in CC, potentially caused by their strong curiosity for adopting other service means including traditional providers. Thus, these people would not stay to a particular application and consistently seek for new experience.

If personality did not predict CC adoption, then what does? Our controls briefly suggest that exposoure to the latest information is the key. Customers who are highly intelligent or at a higher economic class often more knowledgable about recent development of technology. This should be translated into stronger willingness to use CC as their trust strengthens and doubt decreases.

For policy-makers, this study sends a signal on the need to accelerate the efforts for disseminating information about cutting-edge technology to the public. People often seek for assurance on many aspects such as reliability and security before they would commit to use the applications.

Despite its novel attempt, this research is conducted with several caveats. Most importantly, the study framework is very basic. We do not control for product-related variables that are otherwise so widely studied, and our dependent variable is measured in binary rather than capturing how often the respondents use CC.

\section{References}

Albinsson, P.A., \& Perera, B.Y. (2012). Alternative marketplaces in the 21st century: Building community through sharing events. Journal of Consumer Behaviour, 11(4), 303-315.

Antoncic, B. (2009). The entrepreneur's general personality traits and technological developments. World Academy of Science, Engineering and Technology, 53(3), 236-41.

Belk, R. (2014). You are what you can access: sharing and collaborative consumption online. Journal of Business Research, 67(8), 1595-1600.

Böcker, L., \& Meelen, T. (2017). Sharing for people, planet or profit? Analysing motivations for intended sharing economy participation. Environmental Innovation and Societal Transitions, 23, 28-39.

Botsman, R., \& Rogers, R. (2010). What's mine is yours: The rise of collaborative consumption. New York, Harper Collins.

Caligiuri, P.M. (2000). The big five personality characteristics as predictors of expatriate's desire to terminate the assignment and supervisor-rated performance. Personnel Psychology, 53(1), 67-88.

Choi, H.R., Cho, M.J., Lee, K., Hong, S.G., \& Woo, C.R. (2014). The business model for the sharing economy between SMEs. WSEAS Transactions on Business and Economics, $11(2), 625-634$.

Cobb-Clark, D.A., \& Schurer, S. (2012). The stability of big-five personality traits. Economics Letters, 115(1), 11-15.

Felson, M., \& Spaeth, J. (1978). Community structure and collaborative consumption: a routine activity approach. The American Behavioral Scientist, 21(4), 614-624.

Gohary, A., \& Hanzaee, K.H. (2014). Personality traits as predictors of shopping motivations and behaviors: a canonical correlation analysis. Arab Economic and Business Journal, 9(2), 166-174.

Guttentag, D., Smith, S., Potwarka, L., \& Havitz, M. (2018). Why tourists choose Airbnb: A motivation-based segmentation study. Journal of Travel Research, 57(3), 342-359. 
Hamari, J., Sjöklint, M., \& Ukkonen, A. (2015). The sharing economy: why people participate in collaborative consumption. Journal of the Association for Information Science and Technology, 67(9), 2047-2059.

Hamari, J., Sjöklint, M., \& Ukkonen, A. (2016). The sharing economy: Why people participate in collaborative consumption. Journal of the Association for Information Science and Technology, 67(9), 2047-2059.

Hofmann, E., Hartl, B. \& Penz, E., 2017. Power versus trust-what matters more in collaborative consumption? Journal of Services Marketing, 31(6), 589-603.

Hu, Y., Sun, X., Zhang, J., Zhang, X., Luo, F., \& Huang, L. (2009). A university student behavioral intention model of online shopping. 2009 International Conference on Information Management, Innovation Management and Industrial Engineering, 1, 625628.

Lang, C. \& Armstrong, C.M.J. (2018). Collaborative consumption: The influence of fashion leadership, need for uniqueness, and materialism on female consumers' adoption of clothing renting and swapping. Sustainable Production and Consumption, 13, 37-47.

Lee, Z.W., Chan, T.K., Balaji, M.S., \& Chong, A.Y.L. (2018). Why people participate in the sharing economy: an empirical investigation of Uber. Internet Research, 28(3), 829-850.

Leong, L.Y., Jaafar, N.I., \& Sulaiman, A. (2017). Understanding impulse purchase in Facebook commerce: Does Big Five matter? Internet Research, 27(4), 786-818.

McCrae, R.R., \& Costa, P.T. (1990). Personality in Adulthood. New York, Guildford Press.

Milanova, V., \& Maas, P. (2017). Sharing intangibles: Uncovering individual motives for engagement in a sharing service setting. Journal of Business Research, 75, 159-171.

Möhlmann, M. (2015). Collaborative consumption: determinants of satisfaction and the likelihood of using a sharing economy option again. Journal of Consumer Behaviour, 14(3), 193-207.

Ozanne, L.K., \& Ballantine, P.W. (2010). Sharing as a form of anti-consumption? An examination of toy library users. Journal Consumer Behaviour, 9(6), 485-498.

Poon, K.Y., \& Huang, W.-J. (2017). Past experience, traveler personality and tripographics on intention to use Airbnb. International Journal of Contemporary Hospitality Management, 29(9), 2425-2443.

Roccas, S., Sagiv, L., Schwartz, S.H., \& Knafo, A. (2002). The big five personality factors and personal values. Personality and Social Psychology Bulletin, 28(6), 789-801.

Schor, J., \& Fitzmaurice, C. (2015). Handbook on Research on Sustainable Consumption. Cheltenham, Edward Elgar.

So, K.K.F., Oh, H., \& Min, S. (2018). Motivations and constraints of Airbnb consumers: Findings from a mixed-methods approach. Tourism Management, 67, 224-236.

Stephany, A. (2015). The Business of Sharing: Making It in the New Sharing Economy. New York, Palgrave Macmillan.

Tussyadiah, I.P. (2015). An exploratory study on drivers and deterrents of collaborative consumption in travel. In. I., Tussyadiah, \& A., Inversini, (Eds.), Information and Communication Technologies in Tourism 2015 (pp. 817-830). Cham, Springer.

Tussyadiah, I.P. (2016). Factors of satisfaction and intention to use peer-to-peer accommodation. International Journal of Hospitality Management, 55, 70-80.

Tussyadiah, I.P., \& Pesonen, J. (2016). Drivers and barriers of peer-to-peer accommodation staye - an exploratory study with American and Finnish travellers. Current Issues in Tourism, 21(6), 1-18.

Zhang, Y., Phang, C.W., Gu, R., \& Zhang, C. (2019). Antecedents and role of individual sociability on participation in mobile collaborative consumption. Internet Research, 29(5), 1064-1089. 
Zhu, G., So, K.K F., \& Hudson, S. (2017). Inside the sharing economy. International Journal of Contemporary Hospitality Management, 29(9), 2218-2239. 